Bangladesh Journal of Neuroscience 2014; Vol. 30 (2): 69-76

\title{
Study of Sites of Lesion in Ischemic Stroke and Intracerebral Hemorrhage
}

\author{
MD. TAUHIDUL ISLAM CHOWDHURY, MOHAMMAD SHAH JAHIRUL HOQUE CHOWDHURY ${ }^{2}$, \\ SHAMIM AHMED ${ }^{3}$, MURSHED BAQUI ${ }^{4}$, MD. AHSAN HABIB ${ }^{5}$, QUAZI DEEN MOHAMMAD ${ }^{6}$
}

\begin{abstract}
:
Objective: To find out lesion sites in ischemic stroke and intracerebral haemorrhage.

Methodology: This retrospective cross sectional observational study was carried out in the Department of Neurology and Department of Medicine of Dhaka Medical College Hospital. (DMCH), during March, 2010 to February, 2011 in patients admitted with a history of first ever stroke. The duration of the study was one year. For this purpose, a total number of 140 patients, of which 70 were included in ischemic stroke and 70 in intracerebral haemorrhage group. CT scan of head of each patient was done at least 6 hours after the onset of the event.CT diagnosed cases of infarct and ICH were included in this study and subarachnoid haemorrhage cases were excluded. CT negative cases were further investigated by MRI brain when the clinical suspicions of stroke were strong. Results: The mean age of the patients having features of ischemic stroke and intracerebral haemorrhage were $59.81 \pm 11.08$ and 57.21 \pm 10.09 respectively. Male female ratio was 1.92:1 and 1.69:1 in IS group and ICH group respectively. Regarding the risk factor hypertension and smoking were observed most common risk factors in the study patients in both groups. However, diabetes mellitus, arrhythmia, ischemic heart disease and dyslipidemia were observed more common in patients of ischemic stroke than $\mathrm{ICH}$ patients. Among the studied patients, ischemic stroke was observed more common in parietal region (20\% of patients), internal capsule/ capsular region (17.14\% of patients) and caudate nucleus region (10\% of patients). ICH was observed most frequently $32.86 \%(n=23), 15.71 \%(n=11)$ and $5.71 \%(n=4)$ in lentiform nucleus/putamen, thalamus and combined gangliothalamic region respectively. In both group left sided lesion prevailed more than right side. In case of ischemic strokes, left side lesion was $61.43 \%$. In intracerebral haemorrhage, left side lesion was $58.57 \%$. It was also observed that deep intracerebral haemorrhage is the most common location (74.29\%) than the lobar region (25.71\%). Conclusion: Site of predilection of lesions and their distribution pattern differ in ischemic stroke and intracerebral haemorrhage. This study revealed that infarcts were more common in parietal and capsular region and haemorrhage were more common in putamen, thalamus and combined gangliothalamic regions. Ischemic stroke and ICH also have differences in clinical presentation and risk factor profile.
\end{abstract}

Key words: Ischemic stroke, intracerebral hemorrhage

\section{Introduction:}

Stroke is a major cause of mortality and morbidity around the world. It is the third most common cause of death in developed countries after coronary heart disease and cancer $^{1}$. On etiological basis of all strokes about $85 \%$ are ischemic and $15 \%$ are haemorrhagic of which about $10 \%$ are due to $\mathrm{ICH}^{2,3}$.

1. Assistant Professor, National Institute of Neurosciences and Hospital, Sher-E- Bangla, Nagar, Dhaka.

2. Assistant Professor (Resident Physician), National Institute of Neurosciences and Hospital, Sher-E- Bangla Nagar, Dhaka.

3. Assistant Professor, Neurology,Dhaka Medical College \& Hospital, Dhaka

4. Medical Officer, National Institute of Neurosciences and Hospital, Sher-E- Bangla Nagar, Dhaka.

5. Assistant Professor, Neurology,Bangabandhu Sheikh Mujib Medical University, Dhaka.

6. Professor \& Director, National Institute of Neurosciences and Hospital, Sher-E- Bangla Nagar, Dhaka. 
Ischemic stroke occurs either due to thrombosis or embolism involving the cerebral circulation and categorized as small vessel lesion and large vessel lesion ${ }^{4}$. This distinction can usually be made by means of clinical features and more reliably by CT or MRI scanning ${ }^{5}$.Around $70 \%$ of the thrombotic strokes are due to large artery thrombosis and remaining are small infarcts or lacunars infarcts ${ }^{6}$.

Pure cortical stroke tends to be associated with large vessel atherosclerosis and cardiac embolism ${ }^{7}$ Lacunar infarcts are small sub cortical infarcts $(<1.5$ $\mathrm{cm}$ diameter) in the territory of deep penetrating artery usually involving basal ganglia, thalamus, internal capsule, corona radiata, pons, cerebellum ${ }^{6}$. Another type of infarct, the, large subcortical infarct, are also located in cortical territory and supposedly not caused by small vessel disease ${ }^{5}$. In intracerebral hemorrhage, bleeding occurs into brain parenchyma due to rupture of microscopic aneurysm known as Charcot Bouchard aneurysm causing haemorrhage usually involving deeper structure ${ }^{8}$. ICHs were typically located in the basal ganglia (35\%-44\%), thalamus $(10 \%-25 \%)$, subcortical white matter $(19 \%-25 \%)$, cerebellum $(5 \%-10 \%)$, and pons $(5 \%-$ $9 \%$ ). Location is a major determinant of etiology ${ }^{9}$.Deep ICH is usually associated with hypertension and lobar haemorrhage may occur due to amyloid angiopathy, ruptured AVM, coagulopathy, etc ${ }^{10}$.

When stroke is suspected, neuro imaging is done for diagnosis of stroke, subtyping and localization of lesion. A CT scan of head can diagnose haemorrhage immediately but cannot diagnose infarct within 6-12 hours of onset ${ }^{11}$. Diffusion weighted MRI is more sensitive for early brain infarction than standard MR sequence or $\mathrm{CT}^{12}$.

Analysis of lesion locations for groups of patients is important. It can identify areas that have a high probability of being affected by disease ${ }^{13}$. Knowing sites of lesion in stroke patients is helpful in determining risk factor association, formulating immediate and further management plan, and outcome prediction in individual case.

This study is designed to find out pattern of distribution and sites of predilections of lesions in ischemic stroke and intracerebral haemorrhage as evident on CT head or MRI brain and also to evaluate risk factor association and clinical features in ischemic stroke (IS) and intracerebral haemorrhage (ICH).

\section{Methodology:}

Study Design: This was a retrospective cross sectional observational study.

Duration of study: This study was carried out from March 2010 to February 2011 for a period of one year.

Place of study: Department of Neurology and Department of Medicine, Dhaka Medical College Hospital (DMCH), Dhaka.

Study Population: Patients admitted with history of first stroke in Neurology Ward or Medicine Ward.

Sample size: Total sample size was 140 , of which 70 were of ischemic stroke and 70 were of intracerebral haemorrhage.

Selection of Sample: The samples were selected purposively.

Inclusion criteria: Adult patients (Age: equal or more than 18 years), history of first stroke, Presenting within two weeks of onset of illness, evidence of stroke confirmed by CT head or MRI brain, having informed consent.

Exclusion criteria: CT or MRI not showing a relevant lesion, history of recurrent stroke cases of subarachnoid haemorrhage (SAH).

\section{Study procedure:}

Patients admitted in $\mathrm{DMCH}$ through emergency or outpatient department in Neurology ward and Medicine ward with first attack of stroke were enrolled in this study. Detailed history was taken from each patient and thorough physical examination was performed. Partial demographic profiles ie, age, sex, occupation were recorded. Information regarding hypertension, smoking, diabetes, IHD and other relevant history were recorded through a structured questionnaire.

CT scan of head of each patient was done at least 6 hours after the onset of the event and evaluated by a consultant radiologist in the department of Radiology and Imaging, DMCH. CT diagnosed cases of subarachnoid haemorrhage were excluded from the study. CT negative cases were further 
investigated by MRI brain when the clinical suspicion of stroke was strong. MRI evident cases of infarcts were included. Cerebral infarct was defined if CT showed area of low attenuation in the vascular territory that corresponded to recent symptoms and signs or MRI showed relevant T1 hypo intense and T2 I FLAIR hyper intense lesion. ICH was defined when CT scan demonstrated area of hyper density within brain parenchyma with or without ventricular extension. So, 70 cases of cerebral infarct and 70 cases of $\mathrm{ICH}$ were purposively included in the study.

Investigations like complete blood count, urine R/ $\mathrm{M} / \mathrm{E}$, blood sugar (fasting/random), serum creatinine, fasting lipid profile, serum electrolytes and ECG were done for each patient. Regarding risk factors, hypertension was labeled if recorded BP was $140 / 90 \mathrm{~mm} \mathrm{Hg}^{14}$ or patient was on antihypertensive drug .Among smokers, history included number of sticks per day and duration in pack year. Diabetes mellitus was diagnosed when FBS was $7.0-\mathrm{mmol} / \mathrm{L}(126 \mathrm{mg} / \mathrm{dl})$ or RBS $11.1 \mathrm{mmol} /$ $\mathrm{L}(200 \mathrm{mg} / \mathrm{dl}){ }^{15}$ or patient was on anti diabetic medication. Arrhythmia and IHD was diagnosed from suggestive history or ECG findings. Dyslipidaemia was diagnosed if, total cholesterol was $>200 \mathrm{mg} / \mathrm{dl}$ or LDL cholesterol > $130 \mathrm{mg} / \mathrm{dl}$ or Triglyceride > $150 \mathrm{mg} / \mathrm{dl}^{16}$ or patient was on lipid lowering agent.

\section{Analysis of data result:}

The different variables of the data were analyzed with the help of SPSS (Statistical Package for Social Sciences) software version 16 . Statistical analysis was done by appropriate procedure like Chi-square test where applicable. P value d" 0.05 was considered significant with $95 \%$ confidence interval.

\section{Results:}

The mean age of the patients having features of ischemic stroke and intracerebral haemorrhage were $59.81 \pm 11.08$ and $57.21 \pm 10.09$ respectively. Male female ratio was 1.92:1 and 1.69:1 in IS group and $\mathrm{ICH}$ group respectively.

Regarding the risk factor hypertension and smoking were observed most common risk factors in the study patients in both groups. However, diabetes mellitus, arrhythmia, ischemic heart disease and dyslipidaemia were observed more common in patients of ischemic stroke than $\mathrm{ICH}$ patients.

In the current study ischemic stroke was observed in parietal region $(20 \%)$, caudate nucleus and lentiform nucleus $(15.71 \%)$, capsular region $(17.14 \%)$, frontal region $(4.29 \%)$, fronto-parietal region $(4.29 \%)$, thalamic region $(2.86 \%)$, parietooccipital region $(2.86 \%)$, occipital region $(4.29 \%)$, temporo parietal region (2.86\%), and temporal region (2.86\%). ICH was observed most frequently $32.86 \%$ $(n=23), 15.71 \%(n=11)$ and $5.71 \%(n=4)$ in lentiform nucleus/putamen, thalamus and combined gangliothalamic region respectively. In both group left sided lesion prevailed more than right side. In case of ischemic strokes, left side lesion was $61.43 \%$.In intracerebral haemorrhage, left side lesion was $58.57 \%$. It was also observed that deep intracerebral hemorrhage is the most common location $(74.29 \%)$ than the lobar region $(25.71 \%)$.

Table-I

Distribution of the respondents' age by group ( $n=140)$

\begin{tabular}{|c|c|c|c|c|}
\hline \multirow[t]{2}{*}{ Age (In yrs) } & \multicolumn{2}{|c|}{$\begin{array}{c}\text { Ischemic stroke } \\
(n=70)\end{array}$} & \multicolumn{2}{|c|}{$\begin{array}{l}\text { Intracerebral haemorrhage } \\
\qquad(\mathrm{n}=70)\end{array}$} \\
\hline & $\mathrm{n}$ & $\%$ & $\mathrm{~N}$ & $\%$ \\
\hline $18-20$ & 0 & 0.0 & 0 & 0.0 \\
\hline $21-30$ & 1 & 1.43 & 1 & 1.43 \\
\hline $31-40$ & 3 & 4.29 & 2 & 2.86 \\
\hline $41-50$ & 14 & 20.00 & 19 & 27.14 \\
\hline $51-60$ & 17 & 24.29 & 25 & 35.71 \\
\hline $61-70$ & 23 & 32.86 & 14 & 20.0 \\
\hline$>70$ & 12 & 17.14 & 9 & 12.86 \\
\hline Mean $\pm S D$ & \multicolumn{2}{|c|}{$59.81 \pm 11.08$} & \multicolumn{2}{|c|}{$57.21 \pm 10.09$} \\
\hline Range (min-max) & \multicolumn{2}{|c|}{30 to 80} & \multicolumn{2}{|c|}{26 to 75} \\
\hline
\end{tabular}

Table I shows that most cases of ischaemic and haemorrhagic strokes occurred in older age groups (above $40 \mathrm{yrs})$. 
Table-II

Distribution of the respondents according to risk factors $(n=140)$

\begin{tabular}{|c|c|c|c|c|c|}
\hline \multirow[t]{2}{*}{ Risk Factor } & \multicolumn{2}{|c|}{$\begin{array}{l}\text { Ischemic stroke* } \\
(n=70)\end{array}$} & \multicolumn{2}{|c|}{$\begin{array}{c}\text { Intracerebral } \\
\text { haemorrhage }^{*}(n=70)\end{array}$} & \multirow[t]{2}{*}{ pvalue } \\
\hline & $\mathrm{n}$ & $\%$ & $\mathrm{n}$ & $\%$ & \\
\hline Hypertension & 48 & 68.57 & 54 & 77.14 & 0.254 \\
\hline Smoking & 36 & 51.43 & 31 & 44.29 & 0.397 \\
\hline Diabetes mellitus & 32 & 45.71 & 20 & 28.57 & 0.035 \\
\hline Arrhythmia & 13 & 18.6 & 4 & 5.71 & 0.019 \\
\hline Ischemic Heart Disease & 23 & 32.86 & 11 & 15.71 & 0.018 \\
\hline Dyslipidaemia & 27 & 38.57 & 14 & 20.00 & 0.015 \\
\hline
\end{tabular}

* Multiple responses

Table II shows Hypertension, Smoking, DM and Dyslipidaemia were common risk factors for both Ischaemic and Haemorrhagic stroke.

Table-III

Distribution of the respondents according to site of lesion ( $n=140)$

\begin{tabular}{|c|c|c|c|c|c|}
\hline \multirow[t]{2}{*}{ Region } & \multicolumn{2}{|c|}{$\begin{array}{l}\text { Ischemic stroke* } \\
(\mathrm{n}=70)\end{array}$} & \multicolumn{2}{|c|}{$\begin{array}{c}\text { Intracerebral } \\
\text { haemorrhage* }(n=70)\end{array}$} & \multirow[t]{2}{*}{ pvalue } \\
\hline & $\mathrm{n}$ & $\%$ & $\mathrm{n}$ & $\%$ & \\
\hline Frontal region & 3 & 4.29 & 3 & 4.29 & 0.676 \\
\hline Parietal region & 14 & 20.00 & 4 & 5.71 & 0.011 \\
\hline Occipital region & 3 & 4.29 & 2 & 2.86 & 0.500 \\
\hline Temporal region & 2 & 2.86 & 3 & 4.29 & 0.500 \\
\hline Fronto parietal region & 3 & 4.29 & 2 & 2.86 & 0.500 \\
\hline Parieto Occipital region & 2 & 2.86 & 1 & 1.43 & 0.500 \\
\hline Temporo parietal region & 2 & 2.86 & 1 & 1.43 & 0.500 \\
\hline Internal Capsule & 12 & 17.14 & 2 & 2.86 & 0.004 \\
\hline Caudate nucleus & 7 & 10.0 & 1 & 1.43 & 0.031 \\
\hline Lentiform nucleus/Putamen & 4 & 5.71 & 23 & 32.86 & 0.001 \\
\hline Thalamus & 2 & 2.86 & 11 & 15.71 & 0.008 \\
\hline Midbrain & 2 & 2.86 & 1 & 1.43 & 0.500 \\
\hline Pons & 3 & 4.29 & 4 & 5.71 & 0.500 \\
\hline Medulla oblongata & 3 & 4.29 & 2 & 2.86 & 0.500 \\
\hline Cerebellum & 3 & 4.29 & 4 & 5.71 & 0.359 \\
\hline Combined Gangliothalamic & 0 & 0.0 & 4 & 5.71 & 0.042 \\
\hline Multiple sites & 5 & 7.14 & 2 & 2.86 & 0.220 \\
\hline
\end{tabular}

Table III shows that ischaemic stroke most commonly occurred in Parietal cortical region (20\%) and in Internal Capsular region (17.14\%) while ICH were commonly found in Lentiform nucleus/ Putamen region $(32.86 \%)$. 
Table-IV

Distribution of the respondents according to side of lesion $(n=140)$

\begin{tabular}{|c|c|c|c|c|c|}
\hline \multirow[t]{2}{*}{ Side of lesion } & \multicolumn{2}{|c|}{$\begin{array}{l}\text { Ischemic stroke* } \\
(\mathrm{n}=70)\end{array}$} & \multicolumn{2}{|c|}{$\begin{array}{c}\text { Intracerebral } \\
\text { haemorrhage }^{*}(n=70)\end{array}$} & \multirow[t]{2}{*}{ pvalue } \\
\hline & $\mathrm{n}$ & $\%$ & $\mathrm{n}$ & $\%$ & \\
\hline Left & 43 & 61.43 & 41 & 58.57 & \\
\hline Right & 27 & 38.57 & 29 & 41.43 & \\
\hline
\end{tabular}

Table IV shows left predominance of both ischaemic and haemorrhagic stroke (left ischaemic stroke $61.43 \%$ and left ICH $58.57 \%$ )

Table-V

Distribution of the $\mathrm{ICH}$ respondents according to Lobar \& Non Lobar type $(n=70)$

\begin{tabular}{lcc}
\hline Lobar/Non Lobar & $\begin{array}{c}\text { Number of } \\
\text { patients }(n=70)\end{array}$ & Percentage \\
\hline Lobar & 18 & 25.71 \\
Non Lobar & 52 & 74.29 \\
\hline
\end{tabular}

Table $V$ shows $74.29 \%$ of patients developed nonlobar and $25.71 \%$ developed lobar ICH.

\section{Discussion:}

The present study was carried out with an aim to find out distribution of lesion sites in ischemic stroke and intracerebral haemorrhage. The clinical features, risk factors and the partial demographic profile (i.e. age, sex and occupation) of the patients were also evaluated. A total number of 140 patients were included in this study. Number of patients in each group was 70 . In ischemic stroke, age group range was 30 to 80 years and in intracerebral haemorrhage, age group range was 26 to 75 years.

In the current study, the mean age of patients having features of ischemic stroke was found $59.81 \pm 11.08$ years ranging from $30-80$ years and maximum number $(32.86 \%)$ was found in the age group of 61 to 70 years. On the other hand, the mean age of the patients having features of intracerebral haemorrhage was $57.21 \pm 10.09$ years ranging from 26 to 75 years and the highest frequency $(35.71 \%)$ was found in the age group of 51 to 60 years.

In the current study HTN and smoking emerges as the most important and common risk factor in both ischemic stroke and hemorrhagic stroke. Among the studied patients $68.57 \%$ and $55 \%$ patients of ischemic stroke and $77.14 \%$ and $50 \%$ patients of hemorrhagic stroke were hypertensives and smokers respectively. Mohammad et al. (2003) found in their study, $67 \%$ of stroke patients were hypertensive 17. According to Siddique et al (2009) study, smoking appeared as an important risk factor in both hemorrhagic and ischemic stroke ${ }^{18}$. According to Karapanayiotides et al (2004), ischemic stroke was more prevalent in diabetics and haemorrhagic stroke was significantly less prevalent in diabetics i.e. diabetic individuals had a lower relative prevalence of intracerebral haemorrhage ${ }^{19}$. These findings also correlate with the present study where significantly higher diabetic patients (45.71\%) were present in ischemic group than hemorrhagic group $(28.57 \%)$ .Rahman et al. (2001) found significant relation of ischemic heart disease with ischemic stroke, which supports the present study ${ }^{20}$. On the other hand Sarker et al. (2008) observed association of dyslipidaemia in ischemic stroke especially cortical type $^{21}$. In the current study dyslipidaemia shows significant association in ischemic stroke, this matches with the study.

In the current study ischemic stroke was observed in parietal region $(20 \%)$, caudate nucleus and lentiform nucleus $(15.71 \%)$, capsular region (17.14\%), frontal region (4.29\%), fronto-parietal region $(4.29 \%)$, thalamic region $(2.86 \%)$, parieto occipital region (2.86\%), occipital region (4.29\%), temporo parietal region ( $2.86 \%$ ), and temporal region $(2.86 \%)$ which almost matches with the study of Rahman, Quddus and Salahuddin (1998). Rahman, Quddus and Salahuddin (1998), found distribution of cerebral infarct in the following locations such as parietal region (27\%), basal ganglia (20\%), capsular region $(16 \%)$, frontal region $(6 \%)$, fronto parietal 
region (5\%), thalamic region (3\%), parieto-occipital region (3\%), occipital region (3\%), temporo parietal region (3\%), brainstem (2\%), temporal region (1\%), extra capsular(1\%), pontine region $(1 \%)^{22}$. Siddique et al. (2009) observed ischemic stroke in cortical region $(58.75 \%)$, internal capsular region $(12.25 \%)$, basal ganglia region $(6.25 \%)$, insula $(5 \%)$, thalamus (7.5\%), cerebellum (7.75\%) and multifocal $(2.5 \%)$ 18 .According to Rahman, Quddus and Salahuddin (1998) findings, maximum number of infarct was found in parietal region followed by basal ganglia and capsular region ${ }^{22}$. The present study depicted that parietal region and capsular regions are the commoner sites of infarction.

Singh et al. (2006) observed the sites of intracerebral hemorrhages in order of frequency were putamen $(65 \%)$, lobar $(17 \%)$, thalamus $(13 \%)$, Pons $(3 \%)$ and cerebellum (2\%) which is comparable with the present study where the frequency of putamen, lobar, thalamus, pons and cerebellum are $32.86 \%$, $25.71 \%, 15.71 \%, 5.71 \%, 5.71 \%$ respectively ${ }^{23}$. In the current study intracerebral hemorrhages were also observed in combined gangliothalmic region $(5.71 \%)$, medulla oblongata $(2.86 \%)$, mid brain $(1.43 \%)$, Caudate nucleus $(2.86 \%)$ and multiple sites $(2.86 \%)$. On the other hand, Tatu et al. (2000) found the locations of intracerebral hemorrhages were lobar $(36.5 \%)$, lenticular $(32 \%)$, thalamic $(15.7 \%)$, cerebellar (8.8\%), midbrain and pons $(2 \%)$, intraventricular $(2 \%)$, caudate $(1 \%)$ and multiple $(2 \%)^{24}$. Siddeque et al. (2009) also found ICH in cortical region (65\%), internal capsular region $(0 \%)$, basal ganglia region (25\%)insula $(0 \%)$, thalamus $(5 \%)$, cerebellum $(5 \%)$ and multifocal $(5 \%)^{18}$. Junko Nagura et al. (2005) found the lesion sites of intracerebral haemorrhage in putamen (32\%), thalamus (29\%), combined haemorrhage in putamen and thalamus $(3 \%)$, subcortex $(16 \%)$, cerebellum $(8 \%)$, pons $(7 \%)$, caudate nucleus $(0.7 \%)$ or others $(2 \%)^{25}$.

Regarding the most common sites of lesion in haemorrhagic stroke, Abro et al. (2007) found putamen $(51.8 \%)$ followed by thalamus $(33.3 \%)^{26}$. Nagura et al. (2005) observed intracerebral hemorrhages were more frequent in putamen (32\%), and thalamic region $(29 \%)^{25}$. Hadi et al. (2010) estimated more haemorrhage in basal ganglia region ${ }^{26}$.Singh et al. (2006) observed the sites of intracerebral hemorrhages in order of frequency were putamen $(65 \%)$, followed by lobar ( $17 \%)$, thalamus $(13 \%)^{23}$.All these findings support the current study where the most common lesion site of intracerebral hemorrhages were putamen followed by thalamus. In the present study, cerebral infarct in internal capsular region was significantly higher than hemorrhage, which is comparable to Siddeque et al. (2009) study where they found ischemic stroke in internal capsule $(12.25 \%)^{18}$. In the current study ischemic stroke in parietal region and caudate nucleus region were also significantly higher than haemorrhagic stroke.

In the current study, haemorrhage in putamen region, thalamic region and combined gangliothalamic region were significantly higher than infarct. Abro et al (2007) found in putamenial haemorrhage and thalamic haemorrhage were $51.8 \%$ and $33.3 \%$ respectively, which were significantly higher than cerebral infarcts ${ }^{27}$. These findings support the present study.

According to study of Flaherty, Deep ICH was the most common location (36-67\%), followed by lobar $\mathrm{ICH}(15-25 \%)$, cerebellar(7-11\%) and brain stem haemorrhage (4-9\%) which is comparable to the present study, where deep ICH or non-lobar ICH $(74.29 \%)$ is the most common location followed by lobar ICH $(25.71 \%)^{28}$.

In the current study both infarct and haemorrhage were found more on left side of brain. In a study by Rahman, (1998) of the patients of ischemic stroke, showed that the commonest side lesion was the left side of the brain ${ }^{22}$.So variations in distribution of lesion sites occur in ischemic stroke and intracerebral hemorrhage.

\section{Conclusion:}

Site of predilection of lesions and their distribution pattern differ in ischemic stroke and intracerebral haemorrhage. This study revealed that infarcts were more common in parietal and capsular region and haemorrhage were more common in putamen, thalamus and combined gangliothalamic regions. Ischemic stroke and $\mathrm{ICH}$ also have differences in clinical presentation and risk factor profile. 


\section{References:}

1. Poungvarin N. Stroke in developing world. Lancet; 352 (suppl III): 1998; 19-22.

2. Lindsay KW and Bone I. 1997, Neurology and Neurosurgery Illustrated, 3rd ed. Churchill Livingstone; p-237.

3. Biller J, Betsy B, Love, Michael J, Schneck 2008. Intracerebral Haemorrhage. In: Bradley WG, Daroff RB, Fenichel GMJankovic J eds. Neurology in Clinical Practice, $5^{\text {th }}$ ed.; vol 2-B; pp 1225.

4. Rovira A, Grivé E, Rovira AM, Sabin AJ. Distribution territories and causative mechanisms of ischemic stroke. Eur Radiol.; 2005;15(3): 416-26.

5. Halkes P HA, Kappelle LJ, Gijn JV, Wijk IV, Peter J, Koudstaal et al. Large Subcortical Infarcts. Stroke; 2006;37:1828-1832.

6. Norrving B. Lacunar infarcts: no black holes in the brain are benign. Pract Neurol; 2008;8: 222-28

7. Brogger J C, Naess H, Idicula T, Andreassen W, Moen G, Kappelle L J et al. Clinical Presentation and Diffusion Weighted MRI of Acute Cerebral Infarction. The Bergen Stroke Study. BMC Neurol.; 2009;9: 44 -54.

8. Sutherland GR and Auer RN. Primary intrecerebral hemorrhage. J Clin Neurosci; 2006;13: 511-517.

9. Maria Sessa. Intracerebral hemorrhage and hypertension. Neurol Sci 2008;29: 258-259

10. Ariesen MJ, Claus SP, Rinkel GJE, Algra A. Risk factors for intracerebral hemorrhage in the general population. A systematic review. Stroke; 2003;34: 2060-66.

11. Becker J U, .-. Morgenstern LB, Hemphill JC, Anderson C, Broderick JP, Connolly ES et al. Guidelines for the management of spontaneous intracerebral hemorrhage. Stroke; 2010;41(9): 2108-29.

12. Meyer JR, Gutierreza A, Mocka B, Hebrona D, Pragera JD, Michael T. Goreya et al. Highb-value Diffusion-weighted MR imaging of suspected brain infarction. American Journal of Neuroradiology ; 2000;21:1821-1829.

13. Jongen C., Nederkoorn P.J., Niessen W.J., Pluim J.P.W. Investigative Radiology; 2004;39 (8): 462-469

14. JNC 7 (The Seventh report of the Joint National Committee on Prevention, Detection, Evaluation, and Treatment of High Blood Pressure) 2003.JAMA; 289:2560-2577

15. WHO (World Health Organization) 2006. Definition, diagnosis and classification of Diabetes mellitus and intermediate hyperglycemia. Geneva, World Health Org. p 3.

16. NCEP 2001 (National Cholesterol Education Program). Third Report of the Expert Panel on Detection, Evaluation, and Treatment of High Blood Cholesterol in Adults (ATP III). JAMA; 2001;285:(19)2486-97.

17. Mohammad QD, Arif SM, Khan KZ A, Khan NI. Relation of hypertension with stroke-A study of 100 cases. Bangladesh Journal of Neuroscience; 2003;19 (2): 59-64.

18. Siddique AN, Nur Z, Mahbub MS, Alam MB, Miah MT.. Clinical presentation and epidemiology Stroke - a study of 100 cases. J Medicine; 200910: (2)86-89.

19. Karapanayiotides T, Jozwiak PB, Melle VG, Bogousslavasky J, Devuyst G. Stroke patterns, etiology, and prognosis in patients with diabetes mellitus. Neurology; 2004;62:(9)1558-62.

20. Rahman KM, Haque A, Ullah AKM. , Khan R $\mathrm{K}$, Alam MB. Study of modifiable risk factors for Ischaemic Stroke. Bangladesh journal of Neuroscience; 2001;17 (1): 6-9.

21. Sarker T K, Kuddus MR, Khan MR K, Ullah AK M, Islam MR, Haque A. Dyslipidemia in Cortical Versus Subcortical infarction. Bangladesh journal of Neuroscience; 2008;24(1): 24-33.

22. Rahman SM, Quddus MA, Azad SA. CT (Computer Tomographic) evalution of 1000 cases of cerebral infarct. Bangladesh Journal of Radiology and Imaging; 1998;6 (2): 45-50. 
23. Singh J AK, Brogen Ak, Singh KH., Singh J W, Singh B N. CT scan as a Tool for Predicting Outcome of Stroke due to Intracerebral Haemorrhage at a Referral Hospital. IJPMR ; 2006;17 (2) :33-38.

24. Tatu L, Moulin T, Mohamad ER, Vuillier F, Rumbach L, Czorny A. Primary Intracerebral Hemorrhages in the Besançon Stroke Registry. Eur Neurol; 2000;43:(4) 209-214.

25. Nagura J, Suzuki K, Hayashi M, Sakamoto T, Oishi $\mathrm{H}$, Hayashi K. et al. Stroke subtypes and lesion sites in Akita, Japan. Journal of Stroke and Cerebrovascular Disease; 2005;14 (1).
26. Hadi N, Ullah Z, Khursheed H. Awan, Iqbal N. CT Scan Findings in Cerebrovascular Disease: A Local Experience. J. Med. Sci.; 2010;18 (1): 26-28.

27. Abro A, Abbasi MA, Hafeezullah, Sammo J, Sheikh M. Incidence of stroke in context of hypertension in Local Population. Pak J Physiol; 2007;3 (2): 20-27.

28. Flaherty ML, Woo D, Haverbusch M, Sekar P, Khoury J, Sauerbeck L, et al. Racial variations in location and risk of intracerebral hemorrhage. Stroke. 2005;36 (5): 934-937. 